\title{
Responses to: pregnancy-associated lung cancer: a clinical and scientific challenge more than treatment dilemma
}

\author{
Yun-Ting He ${ }^{1}$, Lei Yang ${ }^{2}$, Wei-Chi Luo ${ }^{2}$, Qing Zhou ${ }^{3}$ \\ ${ }^{1}$ Department of Oncology, Maoming People's Hospital, Maoming, China; ${ }^{2}$ The Second School of Clinical Medicine, Southern Medical University, \\ Guangzhou, China; ${ }^{3}$ Guangdong Lung Cancer Institute, Guangdong Provincial People's Hospital, Guangdong Academy of Medical Sciences, \\ Guangzhou, China \\ Correspondence to: Qing Zhou, MD, PhD. Guangdong Lung Cancer Institute, Guangdong Provincial People’s Hospital, 106 Zhongshan 2nd Road, \\ Guangzhou 510080, China. Email: gzzhouqing@126.com. \\ Response to: Zhuang W, Qiao G. Pregnancy-associated lung cancer: a clinical and scientific challenge more than treatment dilemma. J Thorac Dis \\ 2021;13:5572-4.
}

Submitted Aug 14, 2021. Accepted for publication Aug 25, 2021.

doi: $10.21037 /$ jtd-21-37

View this article at: https://dx.doi.org/10.21037/jtd-21-37

We thank Dr. Zhuang and Professor Qiao's comments on our paper. It is a great honor to have the opportunity to discuss pregnancy-associated lung cancer in public. Their comments were highly insightful and enabled us to further investigate this topic. In the following pages were our pointby-point responses to each of the comments. We hope that our responses will be sufficient to dispel the doubts.

The figure in Dr. Zhuang's commentary article was drawn based on the relationship between the timing of symptom onset and diagnosis and the serum change of sex hormones of 11 pregnancy-associated lung cancer patients in Guangdong Lung Cancer Institute. This figure is detailed and intuitive to be easily understood. Dr. Zhuang accordingly suggested that the symptoms of patients worsened rapidly, and most patients were diagnosed in the period of high level of sex hormones, indicating that increased serum level of sex hormones might promote the progression of lung cancer.

Estrogens might be an unfavorable prognostic factor and contribute to carcinogenesis in non-small cell lung cancer (1-3). The early detection and treatment of lung cancer before pregnancy improve the prognosis of pregnancyassociated lung cancer patients. But we have carefully checked again the medical records of the 11 patients in Guangdong Lung Cancer Institute and regretfully found that there was no chest imaging formation before pregnancy, including X-ray or CT. Women of childbearing age, usually younger than 40 years old, are not high-risk lung cancer populations, so they will not receive lung cancer screening routinely. In addition, considering the effects of radiation exposure on offspring, expectant mothers usually avoid CT/X-ray examinations before the pregnancy. What kind of women should receive a chest examination routinely before pregnancy? What is the best timing to do the chest examination? What kind of examination is the suitable method for them? All these questions are important and complicated, but no answer now.

The second requirement is about the TNM staging details. As there was no detailed TNM stage information about the patients collected in the literature, only the TNM stages of the 11 patients in Guangdong Lung Cancer Institute at the time of diagnosis were further checked and shown in Table 1.

Regarding the rapid death reasons in patients without treatment to lung cancer, the specific causes of death were not recorded in this respective study. OS was defined as the time from the diagnosis of lung cancer to death due to any cause, including tumors, pregnancy-related adverse effects, etc. Patients treated during pregnancy, after childbirth, or without any treatments, might die from tumors, adverse effects or any other reasons, too. Patients' outcomes in different groups were influenced by the performance status, pregnancy and childbirth. However, it is not realistic to conduct a perspective study in this special and rare population.

For patient diagnosed with lung cancer during pregnancy 


\begin{tabular}{ll} 
Table 1 TNM Stage of the 11 patients in Guangdong Lung Cancer \\
Institute \\
\hline Patient & TNM Stage \\
\hline 1 & cT2aN1M1a IV \\
2 & cT2N2M1b IV \\
3 & cT4N3M1b IVA \\
4 & cT4N3M1a IVA \\
5 & cT2bN3M1c IVB \\
6 & pT1aN0M0 IA \\
7 & cT4N3M1c IVB \\
8 & cT3N2M1c IVB \\
9 & cT3N2M1a IVA \\
10 & IV \\
11 & Unknown
\end{tabular}

and her family, it is a tough question to determine whether to continue pregnancy or not. It deserves further exploration whether pregnancy termination is reasonable or not. We have collected some important data and explored on this issue. However, due to religious beliefs and different local laws, termination of pregnancy is prohibited in some western countries. There is still a controversy in the law about "Does the fetus have human rights?". Based on these ethical considerations, related content was deleted while writing the article.

As lung cancer cases spurt in females, we should pay more attention to the young female patients and probe the underlying molecular mechanisms. Furthermore, early detection and treatment is also necessary for prepregnancy woman, especially for people who has high risk factors.

\section{Acknowledgments}

Funding: None.

Cite this article as: He YT, Yang L, Luo WC, Zhou Q. Responses to: pregnancy-associated lung cancer: a clinical and scientific challenge more than treatment dilemma. J Thorac Dis 2021;13(10):6102-6103. doi: 10.21037/jtd-21-37

\section{Footnote}

Provenance and Peer Review: This article was commissioned by the editorial office, Fournal of Thoracic Disease. The article did not undergo external peer review.

Conflicts of Interest: All authors have completed the ICMJE uniform disclosure form (available at https://dx.doi. org/10.21037/jtd-21-37). QZ declares speaker fees from AstraZeneca, and Roche. The other authors have no conflicts of interest to declare.

Ethical Statement: The authors are accountable for all aspects of the work in ensuring that questions related to the accuracy or integrity of any part of the work are appropriately investigated and resolved.

Open Access Statement: This is an Open Access article distributed in accordance with the Creative Commons Attribution-NonCommercial-NoDerivs 4.0 International License (CC BY-NC-ND 4.0), which permits the noncommercial replication and distribution of the article with the strict proviso that no changes or edits are made and the original work is properly cited (including links to both the formal publication through the relevant DOI and the license). See: https://creativecommons.org/licenses/by-nc-nd/4.0/.

\section{References}

1. Slatore CG, Chien JW, Au DH, et al. Lung cancer and hormone replacement therapy: association in the vitamins and lifestyle study. J Clin Oncol 2010;28:1540-6.

2. Chlebowski RT, Schwartz AG, Wakelee H, et al. Oestrogen plus progestin and lung cancer in postmenopausal women (Women's Health Initiative trial): a post-hoc analysis of a randomised controlled trial. Lancet 2009;374:1243-51.

3. Chlebowski RT, Wakelee H, Pettinger M, et al. Estrogen Plus Progestin and Lung Cancer: Follow-up of the Women's Health Initiative Randomized Trial. Clin Lung Cancer 2016;17:10-7.e1. 